\title{
Technological Innovation and Resource Bricolage in Firms: The Role of Open Source Software
}

\author{
Aarti Mahajan $^{1, *}$ and Bart Clarysse ${ }^{1,2}$ \\ ${ }^{1}$ Ghent University, Ghent, Belgium \\ ${ }^{2}$ Imperial College, London, UK \\ \{aarti.mahajan, bart.clarysse\}@ugent. be
}

\begin{abstract}
Technological resources have been an important source of innovation in companies. They play a key role in the development of new products and services. However, the upfront investment in technical resources to enable the development of these new products and services can be quite high. Therefore, managers ask for well elaborated business cases before making investments. These business cases rely on market research to back up their assumptions rather than in-market testing. We argue that the advent of open source software (OSS) creates an opportunity space for companies to build low-cost prototypes and test their ideas in the market. Little is known about how OSS plays a role in allowing these firms to enhance product development. Using qualitative case studies, the paper sheds light on how OSS acts as a bricolage mechanism for technological innovation in the ICT services industry.
\end{abstract}

Keywords: Open Source Software, Bricolage, Case study, Resource constraints, Opportunity Recognition, OSS Adoption.

\section{Introduction}

Most firms face substantial resource constraints during firm creation and firm growth (Shepherd et al., 2000). Several authors have studied resource constraints such as lack of finance (Berchicci \& Hulsink, 2006), physical resources constraints (Garud \& Karnoe, 2003) or technological resources constraints (Stuart et al., 1999). Resourceconstrained firms cannot make the necessary upfront investments in technical resources to develop new products and services.

Baker \& Nelson (2005) present Levi-Strauss' (1966) concept of bricolage"making do with what is at hand" as a mechanism to address resource scarcity. Using bricolage, firms are able to create something from nothing by exploring resources which are ignored or rejected by other firms (Baker \& Nelson, 2005). Firms in resource-poor environments typically engage in bricolage by using resources at hand, or by combining resources for new purposes.

Resources at hand typically include personal knowledge and capabilities, initial investment and personal network. However, technological resources may also play an

\footnotetext{
Corresponding author.
} 
important role in bricolage. Technological resources, comprising the technologysoftware, system, platform, etc. are the backbone of the software \& information communication technology (ICT) service industry. The degree of novelty and protection in ICT requires considerable investments in order to access technological resources. A cheaper option for firms is to invest time in developing technology in-house using their technical knowledge and know-how. Open Source Software (OSS) presents an emerging alternative to access technology quickly and cheaply in a context where time and money are crucial. Free availability of source code, zero cost and access to knowledgeable community are the major features of OSS which attract firms to adopt OSS (Fitzgerald, 2006). OSS presents an opportunity space for firms to experiment with technological resources. Moreover, OSS presents several networking opportunities for individuals and firms, enabling 'network bricolage' (Baker et al., 2003).

The literature has so far largely ignored the role of technological resources, and specifically OSS to enable bricolage in the product/service development process. This is an important omission in contexts where technological resources are central to the value proposition of the firm. In this article, therefore, we address the following research question: How do organizations confronted with resource constraints, irrespective of their size and position in the industry life cycle, embrace the opportunity provided by OSS and manage innovation to create value for their firm?

We begin by reviewing the literature on bricolage and OSS adoption. We then introduce the resource pool provided by OSS as a bricolage mechanism in firms to allow technological innovation through experimentation. We proceed to three case studies to examine how OSS as a technological resource facilitates value creation and innovation in micro, small and large firms by allowing them to experiment and bricolage in ICT services industry. We end with results, discussion and conclusions.

\section{The Concept of Bricolage}

The availability of resources presents firms with opportunities to experiment and create value for the firm. Demand and supply gaps lead to opportunity creation, while access to resources confines the choice of opportunities (Thakur, 1999). Availability of resources is highly valuable to young and nascent ventures (Hitt et al., 2001), initially to survive and later to grow (Sirmon \& Hitt, 2003; Hoegl et al., 2008). However, financial, technical and human resources are often not available when required (Bruderl et al., 1992). When discovering opportunities and facing challenges of resource scarcity, entrepreneurs often make decisions using bricolage (Baker \& Nelson, 2005). Bricolage allows these young and nascent ventures to deal with routine problems, and is seen to have a positive effect on innovation in nascent and young firms (Anderson, 2008; Senyard et al., 2011).

Bricolage as a process of resource use and development is conspicuous in firms characterized by resource-poor environments (Baker \& Nelson, 2005). Despite these resource constraints, some ventures survive by solving problems and exploiting opportunities (Mahoney \& Michael, 2005). Levi-Strauss (1966) suggested bricolage as a mechanism for opportunity creation by using resources at hand, recombining resources for new purposes, and making do with existing resources. Previous studies on bricolage in small- and medium-sized enterprises (SMEs) and large organizations 
have been limited to its role in facilitating innovation. Few authors have studied the use of bricolage in ICT firms to develop new products or services (Ciborra, 2002; Ferneley \& Bell, 2006). Ferneley and Bell (2006) studied the concept of bricolage to integrate business and IT innovation in SMEs. SMEs are recognized for their flexibility, and ability to respond rapidly to changing environment, but they are reluctant to adopt information systems, primarily due to lack of strategic planning (Levy et al., 2001) and financial constraints (Foong, 1999). Similarly, MNCs face a number of hurdles which prevents them from reaching their full potential, uncertainty avoidance being the key hurdle (Halme et al., 2012). Halme and colleagues introduced the term intrapreneurial bricolage as entrepreneurial activity within a large organization, characterized by creative bundling of resources, in contexts of resource scarcity (Halme et al., 2012). In order to bricolage, the internal bricoleur- the person who engages in bricolage within an organization, needs organizational space to experiment and innovate (Ferneley \& Bell, 2006). For innovation to occur, the internal bricoleur needs access to technology, which managers are often reluctant to invest in.

While the role of bricolage in innovation has been studied, the literature has largely ignored the resource configuration of firms engaging in bricolage. Several authors have addressed technological resources as key success factors in high technology industries (Henderson \& Clark, 1990; Zahra, 1996; Autio et al., 1997). Not only do technological resources help in formulating the value proposition in the ICT industry, they also play a major role in understanding and evaluating the commercial potential of technological advances (Cohen \& Levinthal, 1990). Research shows that technological knowledge resources impact firm performance (Lee et al., 2001; Clarysse et al., 2011) and that the quality and diversity of technological resources leads to breakthrough innovation (Srivastava \& Gnyawali, 2011). The authors argue that the type of resources plays a key role in value creation for ICT firms The authors further emphasize that technological resources are the backbone of ICT firms, and are a primary source of innovation. The authors propose that availability of technological resources shapes the value proposition of the firm, which in turn facilitates innovation through bricolage.

\section{Open Source Software}

The importance of technological resources in high-technology industries has received ample attention in the management literature. In the ICT industry, ventures need to keep up with the rapid rate of technological evolution. Technological resources in ICT industry are protected by intellectual property rights in the form of patents and copyrights with a view to gain market share and obtain investments from venture capitalists (Bell \& McNamara, 1991). Firms in resource-scarce environments either need to buy these technological resources (software, platform, etc.) or need to reinvent the wheel and develop the technology in-house. With the rapid changes in ICT industry, firms find it difficult to invest time and money in technological resources. Open Source (OS) provides a solution for firms to use technology as a resource at hand, and manage innovation through bricolage. 
Open Source has been widely accepted as a collaborative development process in the software industry. Open Source Software (OSS) is software available in source code form; it can be modified by users, and can be redistributed even in modified form without paying the original developers (Riehle, 2009). Development is undertaken by people dispersed all over the world, forming a virtual community via the Internet (Hertel et al., 2003)

Research on OSS suggests that OSS drives innovation and spurs novel business models (Ebert, 2007). Bonaccorsi and Rossi (2006) observed that a key motivation for OSS entrepreneurial ventures in collaborating with OSS communities was that it allowed small and new firms to be innovative. With a robust, high-quality, featurerich software, and a strong community of developers creating and testing the software, OSS acts as an important source of opportunity for small and large firms. OSS has surpassed the notion of being free software developed by "techies", and is being extensively embraced by organizations owing to its 'high quality at zero cost' facet. Not only individuals and SMEs, but also large corporations and government organizations have depicted a strong increase in adopting OSS. Deploying OSS products in their operation environment as end users has been the most common manner of organizational adoption of OSS (Fitzgerald \& Kenny, 2004; Ven et al, 2008). Hague \& colleagues argue that adopting OSS is more than simply using OSS products (Hauge et al., 2010). Integrating OSS components into one's own software is another popular way of organizational adoption of OSS (Ajila \& Wu, 2007; Ven \& Mannaert, 2008). Participating in OSS development, providing own OSS products, and using OSS development practices within the organization are other ways in which organizations adopt OSS (Hauge et al., 2010).

These studies on OSS adoption have focused more on the collaboration process with the communities and the impact of OSS on firm performance. The key aspect of OSS as an opportunity space and technological resource that drives value creation and technological innovation tends to be sidelined in this research.

\section{OSS Bricolage in Firms}

The concepts of OSS and bricolage have been previously discussed by Feller and Fitzgerald (2002). They addressed the approach of collaborative development in OSS communities, where developers and users bring together their knowledge resources to develop solutions rapidly. The use of these communities enables a process of bricolage. Communities of users and developers interacting over Internet have proved to be valuable innovation inputs (Hargrave \& Van de Ven, 2006). Participation and/or collaboration with a OSS community can facilitate bricolage in firms. We define OSS bricolage as "making use of OS software/platform and the OS community as materials at hand". OSS bricolage may apply to ventures in Software and ICT industry. Starting a business in software and ICT industry is comparatively quite straightforward with the need for few resources. In contrast, industries like biotech, pharmaceuticals and manufacturing are less likely to engage in bricolage due to the high importance assigned to the protection of intellectual property rights.

In ICT, individuals set up micro-firms by exploring the freely available software, while SMEs and large firms tend to exploit the OSS community for their knowledge 
pool. Micro firms are confronted with resource shortage at startup, while SMEs and large firms are keen to expand their resource base in order to grow. OSS not only helps these firms to manage innovation, it also presents several resources for OSS entrepreneurial ventures to build on.

\subsection{Technological Resources}

Technological resources include patents, technological knowledge and skills which are not only valuable, but also difficult to reproduce by other firms (Lee et al., 2001). Patents lead to technological value creation and allow firms to commercialize their intellectual property. In the software sector, copyrights overrule patents. Software code is protected by copyright, while OSS code is freely available under copyleft. Rather than buying expensive licenses on copyright protected software, OSS allows entrepreneurs to experiment and build prototypes with freely available software code. Founders of micro firms and developers in large firms can syndicate their technical knowledge and expertise to work further on the freely available OSS to build their own product/service portfolio.

\subsection{Human Resources}

The acquired knowledge, skills and capabilities of the founders, managers and employees constitute the human resources of the firm (Coleman, 1988). The success of the firm is hugely influenced by qualified managers and founders of the firm (Colombo \& Grilli, 2005). Since human capital focusses on individual attributes, and these ventures tend to be young and small, founders play a critical role in the success of micro firms. Participation in an OSS community enables firms engaging in OSS bricolage to attract knowledgeable developers willing to perform customization of the software.

\subsection{Social Capital Resources}

Several researchers have validated the importance of networks and partnerships for firm performance (Gabbay \& Leenders, 1999; Elfring \& Hulsink, 2003). Social capital allows firm to build up their resource base with the help of other partners. For young and small firms, the social capital resources provide access to information, technical knowledge, market know-how and complementary resources (Eisenhardt \& Schoenhoven 1996; Hitt et al., 2001). Collaboration with OSS communities has displayed positive effect on the innovation performance of the venture (Piva et al., 2012). An OSS community consists not only of the core developers of the software, but also testers, end users and vendors of the software. Owing to their community participation, members tend to know the working of the software as a result of which most of them proceed to form micro firms. The community itself acts as the greatest social capital for these ventures. The community not only helps with development and testing of the software, it can also act as a great marketing and distribution tool for micro firms. Large organizations often allow their developers to work on development of OSS in order to build up their knowledge and professional network. 


\subsection{Financial Resources}

Technology based firms generally require capital in order to invest in R\&D. Firms with access to financial resources are more likely to pursue innovative strategies (Kang 2000; Teece 1992) as financial resources guarantee the firm's survival over longer periods (Dobrazynski, 1993). Lack of financial resources does not affect the performance of OSS micro firms, as the need for significant investments is rare. While keeping costs at minimum, founders of OSS micro firms tend to bootstrap. For SMEs and large firms, adopting OSS instead of their proprietary counterparts helps them cut costs and invest in other activities.

Limited by financial and human resources, firms balance their internal R\&D efforts by networking intensively with external third parties that are likely to contribute valuable knowledge and competences (Stuart \& Sorenson, 2007). With fairly addressable human and financial resources, entrepreneurial ventures regard OSS primarily as a technological and social bricolage mechanism. SMEs and large firms have quite some resources at hand, and OSS as a technical resource can provide them with a platform to expand their value proposition. Moreover, OSS bricolage in these organizations can pave the way for more resources which are necessity for higher levels of innovation (Rothaermel \& Deeds, 2006).

\section{Data and Methods}

In the absence of prior research on the processes of bricolage associated with OSS in ICT service firms, a case study approach seems most appropriate for interpreting these processes (Yin, 1984; Eisenhardt \& Graebner, 2007; Leitch et al., 2010). We adopt a case study approach to explore how dependence on OSS and OSS community helps facilitate technological innovation in ICT service firms. In particular, we examine the nature of the resource configuration associated with OSS in order to develop a framework for OSS adoption in these firms.

There were several reasons to select the ICT services industry: Firstly, owing to the code-sharing conditions enforced by majority of OSS licenses, it is difficult to build commercial products with OSS. Secondly, very few companies provide a $100 \%$ product portfolio. Thirdly, service companies are more likely to innovate with the newer releases of OSS.

In order to look at the adoption of the OSS under different degrees of resource scarcity, we studied its use in a resource-constrained micro-enterprise, a medium sized company which can afford the use of proprietary software while still being in a constraint environment, and a large company which is not resource constrained. We interviewed the founders and/or the department heads of the product development department in each case ${ }^{1}$.

1 Interviews were semi-structured with open-ended questions in English. Two authors conducted the interviews, while a third author was not a part of the interviews in order to avoid any confirmatory biases. The interviews were audio-taped and notes were taken. The interviews were transcribed verbatim and the text was read and re-read several times to identify themes and sub-themes. 
With regards to the micro firm, we interviewed the founders of a Dutch web development company, JWebs. As an initial stage in identifying a suitable micro firm, several micro firms adopting OSS were interviewed at the first Joomla! ${ }^{2}$ international conference. JWebs was considered relevant for the research owing to its size- the two founders never employed any other employees in the five years of company founding, and high dependence on Joomla! OS content management system.

Mobixx represents an example of a Belgian SME trying to carve a space for itself in a niche market of mobile web. Interviews were conducted with two founders and four employees of Mobixx. The company contact was obtained through the professional network of one of the authors. Since one of the founders of Mobixx works in close collaboration with the authors, it was easy to obtain access to the company data throughout the company lifecycle.

To study OSS adoption in a large firm, we interviewed the director of application development of Dutch bank in the Netherlands. The authors identified this case by interviewing five projects relating to intrapreneurship in large organizations. The director had initiated and managed the adoption process from start to finish, and provided the authors with the required information for the case study.

The primary data source is the interviews conducted with the people involved in the bricolage process, namely the founders or department heads. The interview data is complemented by other secondary data- press releases, corporate presentations and company archives, depending on availability.

\section{Bricolage in Micro ${ }^{3}$ Firms: OSS Adoption in a Website Development Company}

In this case, founder1 had a degree in computer science and had used his knowledge to control sound and lights in the theatre industry for nearly two decades. After initially working with the .NET framework, he started coding in PHP in 2007. He founded JWebs in 2007, along with founder2 as a creative designer, with a view to building custom websites and applications. Dynamic websites demanded the use of a content management system (CMS), and founder1 initially built a CMS from scratch using .NET and later reworked it in PHP. He was soon confronted with the difficulties of extending and maintaining the CMS.

"If my customers wanted additional features, I had to write extensions specifically for them. All customers had different requirements, and it was quite time consuming to customize the CMS for each one of them."

2 Joomla! is one of the most popular Open Source content management systems today with a large community consisting of more than 500,000 forum members. Until 2010, Joomla! has been downloaded 25 million times and there are more than 30 million websites running on Joomla

3 We use the definition of the European Commission for defining micro firms as firms with less than 10 employees and turnover of less than 2 million euros : http: / / ec . europa. eu/enterprise/policies/sme/facts-figures-analysis/ sme-definition/index_en.htm 
Having switched to PHP from .NET, he was presented with a wide variety of OS CMS to work with. Fascinated by the community and extendibility of Joomla!, he embraced Joomla! in 2008. Joomla! CMS served the purpose of a PHP-based CMS. Not only was Joomla! easy to work with, but there was also a list of free and cheap extensions available and ready-to-use.

“When I bumped into Joomla!, I realized that I was reinventing the wheel. With Joomla!, I did not need to write specific extensions for customers any more, I could find it or buy it without spending more time developing them myself. Also I did not need to customize them for different websites; the available extensions were ready-to-use."

In comparison to PHP-based OS CMS, very few .NET OS CMS were available in the market at that time. As a result, the extensions for .NET OS CMS were highly priced, and PHP-based OS CMS was the way to go. Customers of JWebs did not know what a CMS was, all they wanted was a good website, and be sure that the website could be easily updated. Since the end users did not care about the backend and just required a website that worked, founder1 decided to migrate all his existing websites to Joomla!.

"Another reason to move towards Joomla! was that it is a community and there is not one person who is at the top making decisions."

The large community of Joomla! also helped the founders to expand their professional network. Activities like Dutch Joomla! days allowed founder1 to meet fellow Joomla! users and developers from Netherlands.

"People interact here and become friends and partners, rather than competitors. At the end of the day, everyone is limited with the number of resources and cannot commit to all projects."

To summarize, JWebs adopted OSS due to its ease of use and extensibility. Over the years, Joomla! has become an integral part of their value proposition. Not only does Joomla! provide these resource-constrained individuals with a free platform for use, it also provides micro companies like JWebs with a space to advertise themselves to the target market. OSS like Joomla! presents a huge potential for extension developers and service providers to set up micro-businesses and make profits by exploiting OSS. As founder1 defended the concept of open source:

"One idea of open source is that you don't put any energy in protecting it, otherwise there is less time spent for coding, and more for workarounds."

\section{Bricolage in SMEs: OSS Adoption in a Small Mobile Internet Company}

The case study presents innovation in a Belgian mobile Internet company with the help of OSS. Mobixx started in 2006, at the time when mobile Internet was still in an early stage of market development. After a first successful pilot project, Mobixx was officially founded in December 2007 with two founders, one project manager, three 
software engineers and four freelance software developers. The value proposition of Mobixx was a technological solution to adapt website content to any mobile device in real time, while adding specific applications like flexible mobile payment system, location specific information, targeted advertisement, etc. The founders were highly dependent on their strong personal and professional network in order to bring the product to market. Due to lack of customer profile, Mobixx was confronted with a diversity of customers who expected high level customization and experimentation with the technology.

"In the beginning, the founder just sold projects to customers. We often had to push reality to deliver everything that was promised to the customer" (Interview with Software Engineer, 16 Nov 2007)

To meet the customer demands, the company had to be flexible with the technological resources they used. This triggered them to use OS components to build part of their value proposition. Use of OS components allowed the developers to easily respond to the varied customer requests. At zero costs, and in no time, the components can be downloaded and used with no need to negotiate and buy a license for use. One of the major components of their technology platform- the device detection database- was based on OS WURFL mobile device database which was continuously updated. The use of OS components enabled the company to instantly respond to opportunities with no significant financial commitment.

"The bazaar model that the open source community uses in the only way to be able to follow the quick innovations that characterize web technologies. Without a large community, maintaining such a project and pushing its possibilities to its limits is impossible.” (Press article, 3 October 2008)

In addition, one of the venture capitalists involved had previously invested in OS companies, instigated by the success story of Red Hat. The venture capitalist intended to push the business model of Mobixx in the direction of Open Source. As a result, Mobixx also provided an OS platform at a later stage under a dual license.

In summary, the evidence from Mobixx suggests that small firms with sufficient resources may be able to benefit from OS in order to widen their value proposition. SMEs are often confronted with speed and timing issues in their early stage, and free availability of technological resources can help strengthen their value proposition and meet their market needs. Technological innovation with the help of OS components assists small organizations in nascent markets to quickly compete with incumbents aiming to be fast followers in their industry.

\section{Bricolage in Large Firms: OSS Adoption in a Large Bank}

The case study involves bricolage at the application development department of Dutch retail bank. In the recent past, Information Technology has come to play an important role at the heart of the banking sector. The banking sector has moved from outsourcing IT services to having its own IT department. Dutch bank has nearly 2000 
employees in their offices in The Netherlands. With the radical changes in information technology, banks are continuously under pressure to have innovative solutions, while being under cost pressure. As the interviewee suggested, the narrow focus on application development at Dutch bank circumvents the need to be entrepreneurial and look for creative solutions in the outside world.

"Last month, I took a week off together with my boss and signed for a fantastic web conference in California. I had a fantastic week with developers of Yahoo! and Facebook. We would have expected our people that actually do the work (of application development) to be there. But there was nobody. People are so frightened and under cost pressure. No team manager allows his people to fly for a week to the States to actually find out what Yahoo! and Google are doing. I truly think there is a great opportunity but also a great need. If we are not careful, in 10 years people will not see the value of bank anymore." (MVD, Director Application Management, Dutch Bank)

After MVD's manager attended a Google conference in 2011, he was impressed by the Android operating system. With MVD's previous IT education and expertise, he and his manager started working on the development of a mobile banking application. Although they had the required background, he did not have formal financial support or dedicated resources from the department. To start with, he needed a software platform to build his application on. MVD went back to his roots and thought about OSS. During his Ph.D. years, he was a Java developer. Contributing to Java had helped him to know the language well and comfortably work with it. They started up a Java community and decided to bricolage, i.e. use resources at hand. Technological resources were no more an issue. Java was freely available, and they had the knowledge of source code. To gather human resources, MVD set up a Java community and encouraged people to come together for free pizzas every Tuesday evening, where they would work on developing something cool. This became an enormous success, and 50 people decided to dedicate their free time to the community. OS technology of screen scrapping was used to evoke the same request normally done by browsers. The knowledge pool resulted in a fully-working mobile application in 2.5 months. This prototype built using OSS answered all questions about the working and feasibility of the application, which normally would not have been possible without resources.

Although they had a fully-working application, the next challenge was to get it into production. Due to several technical reasons, the prototype developed with OSS could not officially advance to production. Additionally, there had been several failures of projects in the past. Thankfully, the prototype proved the success and potential of the mobile application.

"We had a fully-working version but that's not the official way to get into production for many technical reasons. Then you see that it really helped, because all the questions- does it work, is it feasible, they are all gone!" (MVD, Director Application Management, Dutch Bank) 
The only problem that MVD still faced was to institutionalize several processes and get it up and running for the bank. They placed an official program in the application development group to replace the version built in the free time using OSS, with a formally developed application. The success of the prototype gained them credibility and legitimacy, guaranteed them a budget for the development, and also speeded up the development, which was practically impossible with a handful of developers.

Although large organizations are perceived to have several resources at hand, the resources are in fact tightly held and face several constraints. Due to rigid structures and control, employees in large organizations find it difficult to move from their assigned task and work on something creative and entrepreneurial. OSS allows these firms to bricolage in order to seek resources for technological innovation and gain credibility.

\section{Results}

Using qualitative case studies, our aim has been to shed light on how OSS acts as a bricolage mechanism for technological innovation in resource-constrained contexts within the ICT services industry. The degree of bricolage in service firms tends to vary based on the size of the firm. This can be accounted to the difference in the firms' initial resource configuration as well as the growth perspective of the firm. Based on our case study research, table 1 below summarizes the differences in the use of OSS between firms of different sizes.

Table 1. Differences between the three case studies

\begin{tabular}{|c|c|c|c|}
\hline & Micro firm & SME & Large firm \\
\hline Type of OSS & OS project/ system & OS database & OS platform \\
\hline $\begin{array}{l}\text { Dependence } \\
\text { on OSS }\end{array}$ & High & Medium & Medium \\
\hline Use of OSS & Firm level & Firm level & Department level \\
\hline $\begin{array}{l}\text { Type/Degree } \\
\text { of innovation }\end{array}$ & Incremental/ Low & $\begin{array}{l}\text { Incremental/ } \\
\text { Medium }\end{array}$ & Radical/ High \\
\hline $\begin{array}{l}\text { Resources at } \\
\text { hand }\end{array}$ & Software skills & $\begin{array}{l}\text { Software skills, } \\
\text { professional network }\end{array}$ & $\begin{array}{l}\text { Software skills, } \\
\text { professional network, } \\
\text { commercial channels, } \\
\text { infrastructure }\end{array}$ \\
\hline $\begin{array}{l}\text { Resources } \\
\text { needed }\end{array}$ & Technical, Social & Technical, Financial & Technical, Financial \\
\hline Why OSS & $\begin{array}{l}\text { Value offering, } \\
\text { network, marketing } \\
\text { channels }\end{array}$ & $\begin{array}{l}\text { Satisfying } \text { customer } \\
\text { demands, expand } \\
\text { market (Speed and } \\
\text { timing) }\end{array}$ & $\begin{array}{l}\text { Gaining credibility } \\
\text { within firm }\end{array}$ \\
\hline
\end{tabular}


Micro firms startup with scarce resources. Mostly the resources consist of the software skills of the founders, and their expertise based on degree to which they are involved in the OSS community. As a result, they are highly dependent on OSS for technological resources as well as the network. OSS allows them to build their value proposition, while the OSS network provides them with marketing channels and allows them to easily target their customer group. The OSS community helps them build a professional network which opens up possibilities for business partnerships to enable them to work on bigger projects, while still staying small. The regular updates and releases of OSS spurs little innovation opportunities for the service companies, but promises persistence to the firm. For micro OSS firms engaging in extended product development for OSS, innovation opportunities are higher with every new major release of OSS. The speed of innovation for micro firms is influenced by OSS release plan. As a result, micro firms are more likely to work with successful OSS, which is under continuous development by an active community. Micro firms highly dependent on OSS projects and systems tend to remain small, and their future business perspective includes technical superiority and contribution to OSS project, than growth in terms of revenues and employees.

Unlike micro firms, SMEs already have some resources at hand. SMEs have a better insight into market requirements, and the value proposition is already in place at start-up. While software skills and expertise are at hand, SMEs are typically confronted with vague customer demands in a niche market and require more resources due to time constraints. In order to gain competitive advantage in a niche market, SMEs need to satisfy customer requirements by competing on their own expertise, rather than collaborating with peers and OSS community. Speed and timing are crucial in a niche market; SMEs are on a constant lookout for existing technological resources which could add strengthen their value proposition to address varied customer requirements. As seen in our case study, the availability of an OS database can be very useful for SMEs who are faced with time constraints, and hence cannot reinvent the wheel. While dependence of SMEs on OSS is of medium importance, they can benefit from OSS bricolage in order to rapidly adapt their value proposition and expand their customer reach. Free availability of several OSS also allows SMEs to experiment and constantly innovate their value proposition. OSS bricolage in turn helps them to display flexibility and allows them to gain access to financial resources through venture capital.

Large firms are the least likely to be confronted with resource constraints at the firm level, but several departments in large firms find it difficult to get hold of these resources, owing to the hierarchy, control and structure in large firms (Damanpour, 1992; Dougherty, 1992; Halme et al., 2012). Consequently, innovation activity in large firms is limited to specific departments. In spite of the existing knowledge and skills prevalent in some departments, the department heads find it difficult to encourage innovation owing to the lack of resources. Departments in large firms foresee the availability of OSS platforms as a resource-seeking mechanism. As seen in the case of Dutch bank, these departments use OSS platforms to build a working prototype of their products. Working on mature OSS platforms assures high level of security. Departments in large firms profit from OSS bricolage for radical 
innovations. Building working prototype using OSS platforms as technological resource allows these departments to gain credibility within the firms and showcase their innovations to higher management, in order to seek further resources.

\section{Discussion}

Our analysis suggests there are important strategic differences in the way in which OSS is harnessed in resource-constrained firms of different sizes. These differences concern the extent to which OSS is used for exploration or exploitation activities.

Micro firms innovate through OSS bricolage, and explore OSS with a view to strengthening their value proposition and increasing their technical expertise. Micro firms act as real OSS partners and contribute back to the OSS community. However, it is much more difficult for them to exploit OSS as they typically have few customers. Thus, although OSS allows these companies to easily enter the opportunity space and to get off the ground following a lean start-up philosophy (Reis, 2011), it is difficult for them to monetize on OSS. We expect that this is a typical scenario in micro enterprises. Only a few OSS start-ups have escaped this through the attraction of venture capital ${ }^{4}$. Micro OSS firms are comfortable working with successful OSS which is under development by an active community.

In contrast, SMEs are not deterred from experimenting with either developing or mature OSS. Alongside using OSS for iterating their value proposition, they sometimes tend to contribute their expertise back to the OSS, thus exploring and exploiting OSS. As these companies have an installed customer base to which they have sufficient credibility, they can exploit OSS components without taking too much risk. Their customers will pay for the "consulting" rather than straight license fees although the OSS technology is the basis for the work they are doing. Since these companies typically do not have R\&D departments, the OSS community becomes the enlarged $\mathrm{R} \& \mathrm{D}$ department of the company. This implies that these companies also engage in giving "back" to the community and explore at the same time. These companies are probably the most important sources of innovation for the community. For them, OSS resembles open innovation in a true sense.

Finally, large firms play it safe by incorporating mature OSS which has been in the market for a long time, and which tends to pose minimal security risks. Consequently, large firms tend to exploit OSS to gain access to more valuable resources. For large companies, OSS tools have become a sense giving instrument to convince the different management layers that a new product or service can be useful. Especially in an environment such as a bank, where new technologies tend to be cognitively distant from the mainstream understanding in the company, it is important to visualize and even prototype new ideas and services. OSS is an ideal fast and low cost way of

4 For a related research, the authors conducted an online questionnaire survey to study the product developers and service providers for Joomla! OS CMS. Out of the 170 firms, as many as $93 \%$ of the firms started with less than 3 employees, and $91 \%$ of these remained with less than 5 employees within 1-5 years of their founding. None of these 170 firms received any venture capital or external funding. 
prototyping. Without OSS, a traditional business case would have to be made and an upfront investment would be needed. It is unlikely that managers would have been convinced to invest in this.

\section{Conclusion}

In sum, our article makes the following contributions relating to how OSS acts as a bricolage mechanism for technological innovation in the ICT services industry. We have shown that OSS creates an opportunity space. However, that opportunity space is contingent upon different company types. Our case studies show that for micro start-ups, OSS provides an opportunity to explore, but does not easily translate in "exploitation". For SMEs with a customer base, exploitation is more likely and OSS becomes a space for open innovation. In large companies, exploitation is the most likely objective of the use of OSS tools. Overall, these findings provide insights suggestive of how bricolage can be used to access and coordinate technological resources in rapidly changing resource constrained environments. As such, our findings help extend understanding of how different contexts help shape innovative entrepreneurial activity (Zahra and Wright, 2011). We hope that our insights resulting from a focus on analysis of a small number of cases will provide the departure point for future larger studies that encompass further variety in the nature of entrepreneurial ventures adopting OSS.

\section{References}

Ajila, S.A., Wu, D.: Empirical study of effects of open source adoption on software development economics. Journal of Systems and Software 80(9), 1517-1529 (2007)

Alvarez, S.A., Busenitz, L.W.: The entrepreneurship of resource-based theory. Journal of Management 27(6), 755-775 (2001)

Anderson, O.J.: A Bottom-up perspective on Innovations. Administration and Society 40(1), 54-78 (2008)

Autio, E., Yli-Renko, H., Salonen, A.: International growth of Young Technology-based Firms: A resource-based network model. Journal of Enterprising Culture 5(1), 57-73 (1997)

Baker, T., Miner, A.S., Eesley, D.T.: Improvising firms: bricolage, account giving and improvisational competencies in the founding process. Research Policy 32, 255-276 (2003)

Baker, T., Nelson, R.E.: Creating something from nothing: Resource construction through entrepreneurial bricolage. Administrative Science Quarterly 50(3), 329-366 (2005)

Barney, J.B.: Resource-based theories of competitive advantage: A ten-year retrospective on the resource-based view. Journal of Management 27(6), 643-650 (2001)

Barney, J.B., Ketchen, D.J., Wright, M.: The Future of Resource-Based Theory: Revitalization or Decline? Journal of Management 37(5), 1299-1315 (2011)

Bell, C., McNamara, J.: High-tech Ventures: The Guide for Entrepreneurial Success. AddisonWesley Publishing Company, Inc., US (1991)

Berchicci, L., Hulsink, W.: Of Bikes and Men: Innovation patterns and strategic entrepreneurship in the human-powered vehicle sector. Strategic Entrepreneurship: The Role of Networking, Vrije Universiteit Amsterdam, July 3-4 (2006) 
Bonaccorsi, A., Rossi, C.: Comparing motivations of individual programmers and firms to take part in Open Source movement: From community to business. Knowledge, Technology and Policy 18(4), 40-64 (2006)

Bruderl, J., Preisendorfer, P., Ziegler, R.: Survival chances of newly founded business organizations. American Sociological Review 57(2), 227-242 (1992)

Clarysse, B., Wright, M., Van de Velde, E.: Entrepreneurial origin, technological knowledge, and the growth of spin-off companies. Journal of Management Studies 48(6), 1419-1442 (2011)

Cohen, W.M., Levinthal, D.A.: Absorptive-capacity- A new perspective on learning and innovation. Administrative Science Quarterly 35, 128-152 (1990)

Coleman, J.S.: Social capital in the creation of human capital. American Journal of Sociology 94, S95-S120 (1988)

Colombo, M.G., Grilli, L.: Founders' human capital and the growth of new technology-based firms: a competence-based view. Research Policy 34, 795-816 (2005)

Damanpour, F.: Organizational size and Innovation. Organization Studies 13, 375-402 (1992)

Dobrzynski, J.H.: Relationship investing. Business Week 3309, 68-75 (1993)

Dougherty, D.: Interpretive barriers to successful innovation in large firms. Organization Science 3(2), 179-202 (1992)

Ebert, C.: Open Source drives innovation. IEEE Software 24(3), 105-109 (2007)

Eisenhardt, K.M., Schoonhoven, C.B.: Resource-based view of strategic alliance formation: Strategic and social effects in entrepreneurial firms. Organization Science 7(2), 136-150 (1996)

Eisenhardt, K.M., Graebner, M.E.: Theory building from cases: Opportunities and Challenges. Academy of Management Journal 50(1), 25-32 (2007)

Elfring, T., Hulsink, W.: Networks in Entrepreneurship: The case of High- Technology Firms. Small Business Economics 21, 409-422 (2003)

Feller, J., Fitzgerald, B.: Understanding open source software development. Addison Wesley (2002)

Ferneley, E., Bell, F.: Using bricolage to integrate business and information technology innovation in SMEs. Technovation 26(2), 232-241 (2006)

Fitzgerald, B.: The transformation of open source software. MIS Quarterly 30(3), 587-598 (2006)

Fitzgerald, B., Kenny, T.: Developing an information systems infrastructure with open source software. IEEE Software 21(1), 50-55 (2004)

Foong, S.: Effect of end user personnel and systems attributes on computer based information systems success in Malaysian SMEs. Journal of Small Business Management 37(3), 81-87 (1999)

Gabbay, S.M., Leenders, R.T.A.: The structure of advantage and disadvantage. In: Leenders, R.T.A., Gabbay, S.M. (eds.) Corporate Social Capital and Liability, pp. 1-16. Kluwer, New York (1999)

Garud, R., Karnoe, P.: Bricolage versus breakthrough: distributed and embedded agency in technology entrepreneurship. Research Policy 32(2), 277-300 (2003)

Halme, M., Linderman, S., Linna, P.: Innovation for inclusive business: Intrapreneurial bricolage in multinational corporations. Journal of Management Studies 49(4), 743-784 (2012)

Hargave, T.J., Van de Ven, A.: A Collective Action Model of Institutional Innovation. Academy of Management Review 31(4), 864-888 (2006) 
Hauge, O., Ayala, C., Conradi, R.: Adoption of open source software in software-intensive organizations- A systematic literature review. Information and Software Technology 52, 1133-1154 (2010)

Henderson, R.M., Clark, K.B.: Architectural innovation: the reconfiguration of existing product technologies and the failure of established firms. Administrative Science Quarterly 35, 9-31 (1990)

Hertel, G., Neidner, S., Herrmann, S.: Motivation of software developers in Open Source projects: an Internet-based survey of contributors to the Linux kernel. Research Policy 32, 1159-1177 (2003)

Hitt, M.A., Ireland, R.D., Camp, S.M., Sexton, D.L.: Strategic entrepreneurship: Entrepreneurial strategies for wealth creation. Strategic Management Journal 22(6-7), 479$491(2001)$

Hoegl, M., Gibbert, M., Mazursky, D.: Financial constraints in innovation projects: When is less more? Research Policy 37(8), 1382-1391 (2008)

Kang, D.: The impact of family ownership on performance in public organizations. A study of U.S. Fortune 500, 1982-1994. Academy of Management Meeting, Toronto (2000)

Lee, C., Lee, K., Pennings, J.M.: Internal capabilities, external networks, and performance: A study on technology-based ventures. Strategic Management Journal 22(6-7), 615-640 (2001)

Leitch, C.M., Hill, F.M., Harrison, R.T.: The philosophy and Practice of Interpretivist Research in Entrepreneurship: Quality, Validation, and Trust. Organizational Research Methods 13(1), 67-84 (2010)

Levi-Strauss, C.: The Savage Mind. University of Chicago Press, Chicago (1966)

Levy, M., Powell, P., Yetton, P.: SEMs: Aligning IS and the strategic context. Journal of Information Technology 16, 133-144 (2001)

Mahoney, J.T., Michael, S.C.: A subjectivist theory of entrepreneurship. In: Alvarez, S.A., Agarwal, R., Sorenson, O. (eds.) Handbook of Entrepreneurship, pp. 33-53. Kluwer, Boston (2005)

Piva, E., Rentocchini, F., Rossi-Lamastra, C.: Is Open Source software about innovation? Collaborations with the Open Source Community and Innovation Performance of software entrepreneurial ventures. Journal of Small Business Management 50(2), 340-364 (2012)

Reis, E.: The Lean Startup: How today's Entrepreneurs use continuous innovations to create radically successful businesses. The Crown Publishing Group, New York (2011)

Riehle, D.: The Commercial Open Source Business Model. In: Proceedings of Americas Conference on Information Systems (2009)

Rothaermel, F.T., Deeds, D.L.: Alliance type, alliance experience, and alliance management capability in high-technology ventures. Journal of Business Venturing 21(4), 429-460 (2006)

Senyard, J.M., Davidsson, P., Baker, T.: Resource constraints in innovation: The role of bricolage in new venture creation and firm development. In: Maritz, A. (ed.) Proceedings of the 8th AGSE International Entrepreneurship Research Exchange, Swinburne University of Technology, Melbourne, pp. 609-622 (2011)

Shepherd, D.A., Douglas, E.J., Shanley, M.: New Venture Survival: Ignorance, external shocks, and risk deduction strategies. Journal of Business Venturing 15(5-6), 393-410 (2000)

Sirmon, D.G., Hitt, M.A.: Managing resources: Linking unique resources, management and wealth creation in family firms. Entrepreneurship Theory and Practice 27(4), 339-358 (2003) 
Srivastava, M.K., Gnyawali, D.R.: When do relational resources matter? Leveraging portfolio technological resources for breakthrough innovation. Academy of Management Journal 54(4), 797-810 (2011)

Stuart, T.E., Hoang, H., Hybels, R.C.: Interorganizational endorsements and the performance of entrepreneurial ventures. Administrative Science Quartely 44(2), 315-349 (1999)

Stuart, T.E., Sorenson, O.: Strategic Networks and Entrepreneurial Ventures. Strategic Entrepreneurship Journal 1, 211-227 (2007)

Teece, D.J.: Foreign investment and technological development in Silicon Valley. California Management Review 34(2), 88-106 (1992)

Thakur, S.P.: Size of investment, opportunity choice, and human resources in new venture growth: Some typologies. Journal of Business Venturing 14(3), 283-309 (1999)

Ven, K., Mannaert, H.: Challenges and strategies in the use of open source software by independent software vendors. Information and Software Technology 50(9-10), 991-1002 (2008)

Ven, K., Verhelst, J., Mannaert, H.: Should you adopt open source software? IEEE Software 25(3), 54-59 (2008)

Yin, R.K.: Case Study Research: Design and Methods. Sage, London (1984)

Zahra, S.: Technology Strategy and Performance. A study of corporate-sponsored and Independent Biotechnology Ventures. Journal of Business Venturing 11(4), 298-321 (1996)

Zahra, S., Wright, M.: Entrepreneurship's next act. Academy of Management Perspectives 25(4), 67-83 (2011) 